\title{
Antitumor activity of 7-O-succinyl macrolactin A tromethamine salt in the mouse glioma model
}

\author{
JUN JIN ${ }^{1,2}$, SUH HEE CHOI ${ }^{1}$, JUNG EUN LEE ${ }^{1}$, JIN-DEOK JOO ${ }^{1,2}$, \\ JUNG HO HAN $^{1,2}$, SU-YOUNG PARK ${ }^{3}$ and CHAE-YONG KIM ${ }^{1,2}$ \\ ${ }^{1}$ Department of Neurosurgery, Seoul National University Bundang Hospital, Seongnam-si, \\ Gyeonggi-do 13620; ${ }^{2}$ Department of Neurosurgery, Seoul National University College of Medicine, Seoul 03080; \\ ${ }^{3}$ Research and Development Center, Daewoo Pharmaceutical Ind. Co., Ltd., Busan 49393, Republic of Korea
}

Received December 29, 2015; Accepted February 17, 2017

DOI: $10.3892 / \mathrm{ol} .2017 .5918$

\begin{abstract}
Chemoradiotherapy with temozolomide is the current standard treatment option for patients with glioblastoma. However, the majority of patients with glioblastoma survive for $<2$ years. Therefore, it is necessary to develop more effective therapeutic strategies for the treatment of glioblastoma. 7-O-succinyl macrolactin A tromethamine salt (SMA salt), a macrolactin compound, is known to possess an antiangiogenic activity. The present study investigated the antitumor effects of SMA salt in the treatment of glioblastoma by evaluating in vitro and in vivo antitumor effects of SMA salt in an experimental glioblastoma model. The antitumor effects of the drug on human glioblastoma U87MG, U251MG and LN229 cell lines were assessed using in vitro cell viability, migration and invasion assays. Nude mice with established U87MG glioblastoma were assigned to either the control or SMA salt treatment group. The volume of tumors and the duration of survival were also measured. SMA salt affected cell viability and caused a concentration-dependent inhibition effect on the migration and invasion of glioblastoma cell lines. Animals in the SMA salt treatment group demonstrated a significant reduction in tumor volume and an increase in survival $(\mathrm{P}<0.05)$. Treatment with SMA salt presented more cytotoxic effects as well as anti-migration and anti-invasion activity compared with the control group in vitro and in vivo. These results suggest that SMA salt has significant antitumor effects on glioblastoma.
\end{abstract}

Correspondence to: $\mathrm{Dr}$ Chae-Yong Kim, Department of Neurosurgery, Seoul National University Bundang Hospital, 82 Gumi-ro 173 Beon-gil, Bundang-gu, Seongnam-si, Gyeonggi-do 13620, Republic of Korea

E-mail: chaeyong@snu.ac.kr

Key words: glioblastoma, migration, invasion, macrolactin A, 7-O-succinyl macrolactin A tromethamine salt

\section{Introduction}

Glioblastoma constitutes the largest group of brain tumors that respond poorly to present anti-neoplastic therapies (1). Currently, microsurgery and adjuvant concomitant chemoradiotherapy with temozolomide are the recommended first-line treatments for patients with primary glioblastoma (2). Despite advances in the treatment of glioblastoma, the prognosis for patients with newly diagnosed glioblastoma remains poor. The median survival of these patients was 14.6 months when treated with chemoradiotherapy with temozolomide, due to the high invasiveness and heterogeneity of glioblastoma $(3,4)$. Currently, there are no effective therapeutic options to prevent temozolomide resistance. Therefore, it is important to find novel therapeutic agents to overcome treatment resistance to temozolomide.

The major metabolite 7-O-Succinyl macrolactin A (SMA) is generated by Bacillus polyfermenticus KJS-2. SMA has a range of activities including significant antiviral and cancer cell cytotoxic properties $(5,6)$. Recently, SMA has been demonstrated to exhibit inhibitive effects against intestinal inflammation in colon epithelial cells (7) and anti-cell invasion (8). Kang et al (9) suggested that SMA and macrolactin A (MA) effectively inhibited angiogenesis activity in human umbilical vein endothelial cells and emphasized that two agents may be explored for treatment of cancer. Additionally, Regmi et al (10) suggested that SMA may function as a potential monotherapy or combination therapy with 5-FU or cisplatin to demonstrate the antitumor activity with numerous cell line in vivo and in vitro.

To the best of our knowledge, the effect of SMA on brain tumor especially glioblastoma have not been investigated. Therefore, the anti-neoplastic effects of SMA tromethamine salt (SMA salt) on glioblastoma were assessed in vitro and in vivo in the present study. Accordingly, the possibility of utilizing SMA salt as a novel antitumor agent for glioblastoma has been evaluated.

\section{Materials and methods}

Cell culture. Human glioma U87MG, U251MG and LN229 cell lines were originally purchased from the American Type 
Culture Collection (Manassas, VA, USA). These cell lines were cultured in complete Dulbecco's modified Eagle's medium (DMEM) that was supplemented with $10 \%$ fetal bovine serum (FBS). All cells were incubated at $37^{\circ} \mathrm{C}$ in a humidified atmosphere of $5 \% \mathrm{CO}_{2}$.

Drug preparation. SMA salt was prepared in powder form by Daewoo Pharmaceutical Ind. Co., Ltd. (Busan, Republic of Korea). SMA salt was diluted in saline to a concentration of $10 \mathrm{mM}$. DMEM without FBS was used for additional dilutions.

Cell viability assay. The cytotoxicity of the SMA salt from Daewoo Pharmaceutical Ind. Co., Ltd. was measured using the Cell Counting Kit-8 (CCK-8; Dojindo Molecular Technologies Inc., Kumamoto, Japan). CCK-8 contains Dojindo's highly water-soluble tetrazolium salt, which produces a water-soluble formazan dye upon reduction in the presence of an electron mediator. The U87MG, U251MG and LN229 cell lines were seeded into 96 -well plates at a density of $5 \times 10^{3}$ cells/well to allow for overnight adhesion at $37^{\circ} \mathrm{C}$ and $5 \% \mathrm{CO}_{2}$. Subsequent to adhesion, the cells were treated with SMA salt at a concentration of $1,10,100$ and $1,000 \mu \mathrm{M}$ at $37^{\circ} \mathrm{C}$ in $5 \% \mathrm{CO}_{2}$. After 2 days, $10 \mu 1$ of the CCK-8 solution was added to each well of the plate and the plate was subsequently incubated for $2 \mathrm{~h}$ in an incubator $\left(37^{\circ} \mathrm{C} ; 5 \% \mathrm{CO}_{2}\right)$. The optical density (OD) of the sample plate was measured at $450 \mathrm{~nm}$ in a microplate reader. The viability of the tumor cells was assessed by calculating the OD ratio of the specific OD in each sample to the OD of the control sample.

Migration assay. The insert of a 24-well Transwell apparatus (Corning Incorporated, Corning, NY, USA) was incubated at $37^{\circ} \mathrm{C}$ for $1-2 \mathrm{~h}$ to adjust to room temperature. SMA salt-treated $(1,10,100$ and $1,000 \mu \mathrm{M}) \mathrm{U} 87 \mathrm{MG}, \mathrm{U} 251 \mathrm{MG}$ and LN229 cells, and un-treated U87MG, U251MG and LN229 cells as the control $\left(2 \times 10^{5}\right.$ cells $\left./ \mathrm{ml}\right)$, were prepared in serum-free medium. FBS-containing medium $(750 \mu \mathrm{l})$ was added to the lower chamber and $200 \mu \mathrm{l}$ of prepared cell suspension was added to the insert. After $24 \mathrm{~h}$, cells that remained in the insert (i.e., non-invading cells) were gently retrieved using a cotton-tipped swab and allowed to air-dry for $20 \mathrm{~min}$. A solution of $0.4 \%$ crystal violet $(500 \mu \mathrm{l})$ was added to each well of the apparatus. After $10 \mathrm{~min}$, the migrated cells that traversed the membrane separating the insert from the lower chamber were stained by dipping the lower surface of the membrane into the stain. The stained membranes were washed several times using water and allowed to air-dry. The cells that adhered to the membrane were quantified by dissolving the stained cells in $10 \%$ acetic acid and transferring the mixture to a 96-well plate for colorimetric determination of the optical density at $570 \mathrm{~nm}$. These experiments were performed in triplicate.

Invasion assay. Matrigel (BD Biosciences, Franklin Lakes, NJ, USA) was thawed overnight at $4^{\circ} \mathrm{C}$ and diluted $(1-5 \mathrm{mg} / \mathrm{ml})$ in serum-free cold DMEM. A total of $100 \mu \mathrm{l}$ of the diluted Matrigel was added to the upper chamber of a Transwell apparatus and incubated at $37^{\circ} \mathrm{C}$ for $4-5 \mathrm{~h}$ to allow the gel to swell. SMA salt-treated U87MG, U251MG and LN229 cells $\left(2 \times 10^{5}\right.$ cells $\left./ \mathrm{ml}\right)$ were prepared in serum-free medium.
Medium containing FBS $(750 \mu \mathrm{l})$ was added to the lower chamber of the Transwell apparatus and $200 \mu 1$ of prepared cell suspension was added to each insert and incubated at $37^{\circ} \mathrm{C}$ in 5\% $\mathrm{CO}_{2}$. After $24 \mathrm{~h}$, non-invading cells were retrieved and invasive cells were quantified as described above.

Mouse glioblastoma xenograft model. A total of 28 6-week-old female BALB/c-nu mice were purchased from Orient Bio, Inc. (Seongnam, Republic of Korea; Charles River, Wilmington, MA, USA) and maintained at Seoul National University Bundang Hospital Preclinical Research Center in temperatures of $18-22^{\circ} \mathrm{C}$ and an atmosphere of supply air filtered using a HEPA Filter Unit. A total of 10 to 15 fresh air changes per hour were provided in the animal housing rooms with the $100 \%$ Outdoor Air System in a positive pressure room. They were fed with Purina irradiated Lab. Rodent chow 38057, and were maintained in a $12 \mathrm{~h}$ light/dark cycle. The mean weight of the mice was $18.7 \mathrm{~g}$. First, Mice were anesthetized with zoletil. Then the head was fixed in a stereotactic frame and a midline scalp incision was made. A small hole was made $0.5 \mathrm{~mm}$ anterior and $2 \mathrm{~mm}$ lateral to the exposed bregma. A sterile $10 \mu 1$ Hamilton syringe with a \#26S needle was inserted at a depth of $3.5 \mathrm{~mm}$ from the surface of the skull and withdrawn by $0.5 \mathrm{~mm}$ to inject $2 \times 105$ U87MG cells within a volume of $2 \mu \mathrm{l}$. The injection rate was set at $0.5 \mathrm{ml} / \mathrm{min}$. Following the implantation of the tumor cells, the needle was kept in place for $3 \mathrm{~min}$ to prevent reflux. The needle was subsequently completely withdrawn from the brain over the course of $3 \mathrm{~min}(1.0 \mathrm{~mm} / \mathrm{min})$ and the skin was sutured. The present study was approved by the Institutional Animal Care and Use Committee of the Medical Science Research Institute, Seoul National University Bundang Hospital (Gyeonggi-do, Republic of Korea).

Treatment protocol. Tumor-bearing mice were randomly assigned to four groups: control $(n=14)$ and SMA salt $(n=14)$. SMA salt was administered intraperitoneally at a dose of $50 \mathrm{mg} / \mathrm{kg}$ daily in the SMA salt group. Animals in the control group were injected with saline only. A single dose of the drugs was composed of a $5 \mathrm{sec}$ infusion of a volume equaling $5 \mathrm{ml} / \mathrm{kg}$. The drug treatments began 7 days subsequent to the implantation of tumor cells. Half of the animals were sacrificed 1 month subsequent to the implantation of the tumor cells for tumor volume analysis; the remaining animals were observed for another 2 months to analyze their survival. The humane endpoint was defined as a weight reduction of $>25 \%$ of the initial weight. Weight loss in all mice remained above this threshold, and all surviving mice were anaesthetized and humanely sacrificed at the end of the study (11). The mice that did not reach a $25 \%$ reduction in initial weight were humanely anaesthetized and sacrificed (cervical dislocation) at the end of the survival experiment.

Evaluation of tumor growth. Subsequent to being sacrificed, their brains of the mice were removed following vascular perfusion with a solution containing PBS, and fixed with $4 \%$ paraformaldehyde at $4^{\circ} \mathrm{C}$ for 2 weeks for paraffin embedding. The fixed brains were sectioned coronally into slices of $10-\mu \mathrm{m}$ thickness using a microtome. The slices were mounted on individual slides and stained with hematoxylin 
and eosin. The maximal length (L), width (W) and height $(\mathrm{H})$ of each tumor was measured by the Axio Imager A2 microscope and AxioVision x40 software (version 4.8.1.0; Carl Zeiss Microscopy GmbH, Jena, LA, USA), and tumor volume was calculated using the following formula: Tumor volume $=4 / 3 \times \pi \times(\mathrm{L} / 2 \times \mathrm{W} / 2 \times \mathrm{H} / 2)(12)$.

Statistical analysis. All data are presented as the mean \pm standard deviation or are expressed as a percentage of controls \pm standard deviation. The present study used an unpaired t-test and the Kruskal-Wallis test for the statistical analysis of the data. The Kaplan-Meier method was used for the survival analysis of the experimental animals. Differences with regard to survival were tested for significance using the two-sided log-rank test. All analyses were performed using the SPSS statistical software package (version 17.0; SPSS, Inc, Chicago, IL, USA). $\mathrm{P}<0.05$ was considered to indicate a statistically significant difference.

\section{Results}

Effect of SMA salt on cell viability. Prior to examining the effects of SMA salt, the present study confirmed its cytotoxicity in glioblastoma cell lines. The glioblastoma U87MG, U251MG and LN229 cell lines were cultured in the presence of SMA salt at a concentration that ranged between 0 and $1,000 \mu \mathrm{M}$ for different durations (24-48 h). The experiment included a group of cells that were cultured without SMA salt as a negative control group.

A concentration-dependent decrease in cell viability subsequent to exposure to SMA salt was observed at concentration of $1 \mu \mathrm{M}(80.4 \%$ at $24 \mathrm{~h}, \mathrm{P}<0.05 ; 63.8 \%$ at $48 \mathrm{~h}, \mathrm{P}<0.001)$ and $10 \mu \mathrm{M}(88.4 \%$ at $24 \mathrm{~h}, \mathrm{P}<0.05 ; 60.4 \%$ at $48 \mathrm{~h}, \mathrm{P}<0.001)$ in the U87MG and U251MG cell lines, respectively (Fig. 1A and B). At concentrations $>10 \mu \mathrm{M}$, SMA salt significantly inhibited cell viability of the LN229 cell line (Fig. 1C). These results suggest that SMA salt does affect the viability of glioblastoma cell lines.

Effect of SMA salt on cell migration and invasion. To ascertain the influence of SMA salt on the migration of glioblastoma cell lines, Transwell apparatus was used to detect cell migration through the membrane barrier between the Transwell inserts and receptacles. At $48 \mathrm{~h}$, SMA salt decreased the migration ability of glioblastoma cells in concentration-dependent manner (Fig. 2A and B). In the U87MG and U251MG cell lines, SMA salt concentrations of $10 \mu \mathrm{M}$ and $100 \mu \mathrm{M}$ resulted in a migration capacity that was 2 -fold and 10-fold lower, respectively, compared with the control group. In the LN220 cell line, SMA salt also significantly inhibited the migration of glioblastoma cells at concentrations $>0 \mu \mathrm{M}$ (Fig. 2C). In addition, a significant inhibition of cell invasion was observed in each of the cell lines; the percentage inhibition of invasion at a concentration of $100 \mu \mathrm{M}$ was $\sim 50 \%(\mathrm{P}<0.05)$ in all cell lines (Fig. 2D-F). SMA salt treatment significantly decreased the migration ability and invasion potential of glioblastoma cells in a concentration-dependent manner. These results demonstrate that treatment with SMA salt clearly inhibits cell migration and invasion.
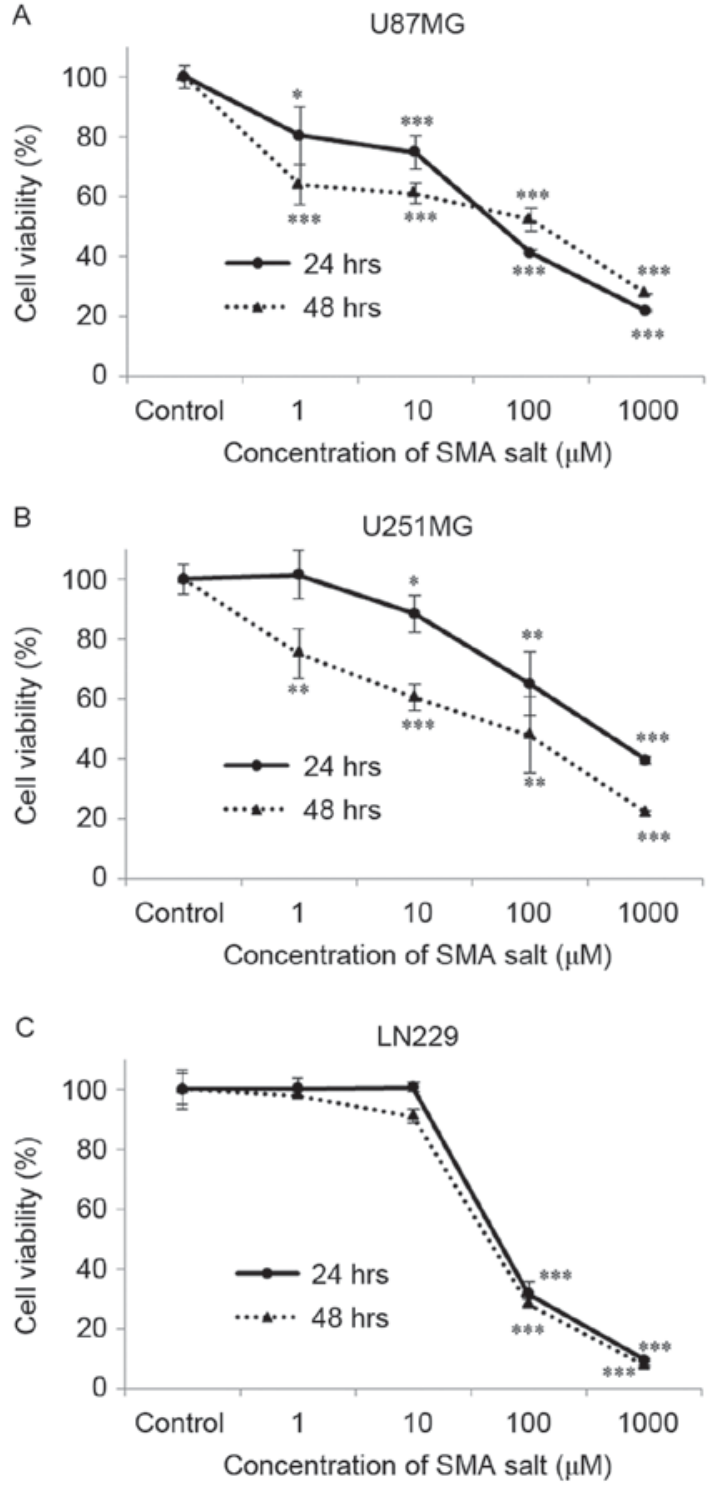

Figure 1. Effect of SMA salt on cell viability in (A) U87MG, (B) U251MG and (C) LN229 cell lines. Cells were treated with SMA salt at 1, 10, 100 and $1,000 \mu \mathrm{l}$ for 24 and $48 \mathrm{~h}$, and the cell viability was then analyzed utilizing the CCK-8 assay. All values represent the mean \pm SD of three independent experiments analyzed by Student's $t$-test. ${ }^{*} \mathrm{P}<0.05,{ }^{* *} \mathrm{P}<0.01$ and ${ }^{* * *} \mathrm{P}<0.001$ vs. control. SMA, 7-O-succinyl macrolactin A; SMA salt, SMA tromethamine salt.

Effect of SMA salt on glioma growth. The in vivo antitumor effect of SMA salt was estimated in tumor-bearing nude mice. A tumor volume analysis was performed using mice that were euthanized 1 month following tumor cell implantation (Fig. 3). The mean tumor volume of the SMA salt group $\left(3.81 \pm 1.91 \mathrm{~mm}^{3}\right)$ was significantly smaller compared with the control group $\left(11.34 \pm 6.86 \mathrm{~mm}^{3} ; \mathrm{P}=0.013\right)$.

Effect on SMA salt on survival. Survival analyses of the control and SMA salt groups were performed (Fig. 4). The median survival of the control and SMA salt groups were 57 [95\% confidence interval (CI), 39-75] and 92 days (95\% CI, 79-105), respectively. The overall survival of the SMA salt group was significantly higher compared with the overall survival of the control group $(\mathrm{P}=0.006)$. 
U87MG

A

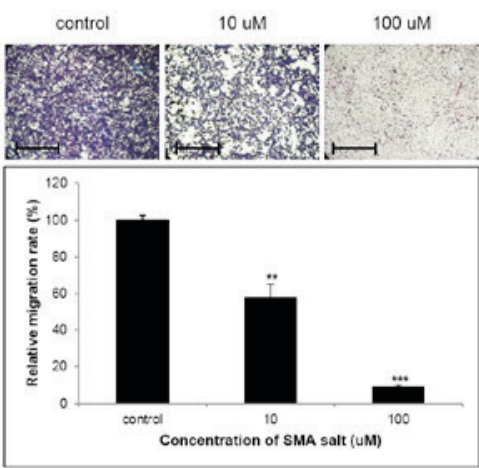

D
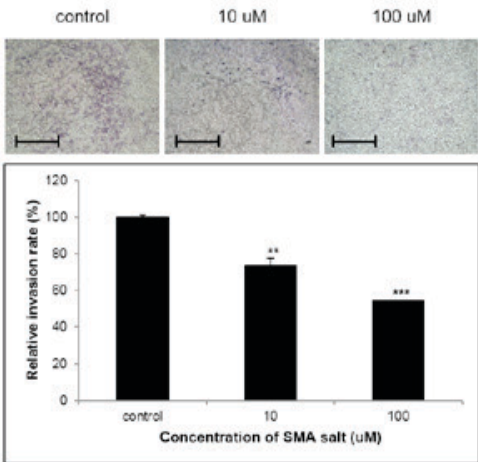

U251MG

B
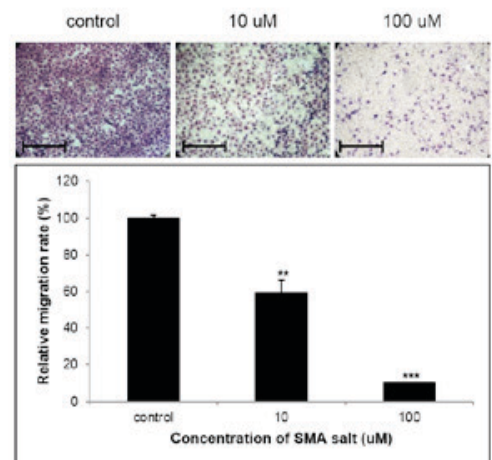

E
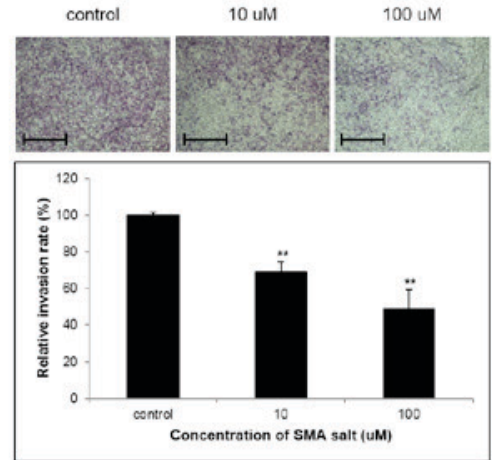

LN229

C
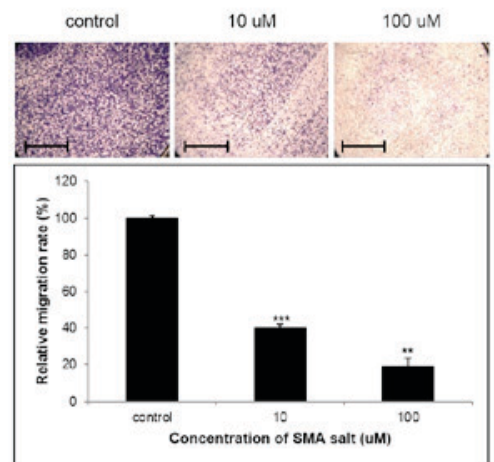

$\mathrm{F}$
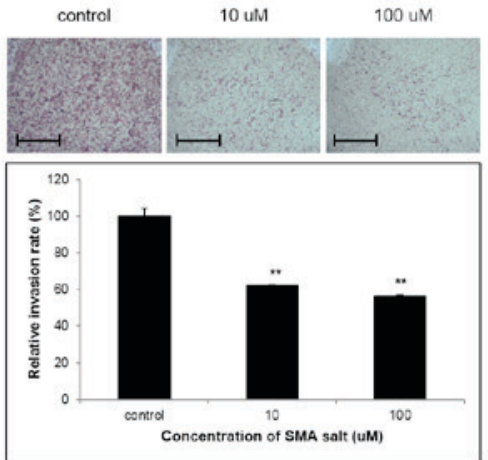

Figure 2. Effect of SMA salt on cell migration and invasion. Cells were treated with 10 and $100 \mu 1$ SMA salt for $48 \mathrm{~h}$ and the cell migration and invasion ability was analyzed utilizing a Transwell assay. Results from the cell migration assay using glioblastoma (A) U87MG, (B) U251MG and (C) LN229 cell lines. The invasion ability of glioblastoma (D) U87MG, (E) U251MG and (F) LN229 cell lines utilizing a Matrigel invasion assay. Cells that invaded to the lower surface of the membrane were stained with crystal violet. The purple color indicates migrated cells that acquired the stain. Original magnification, $\mathrm{x} 100$. The scale bar on all images from A to F was $35.29 \mathrm{um}$. All values represent the mean \pm standard deviation of two independent experiments analyzed by Student's t-test. $\left({ }^{* *} \mathrm{P}<0.01,{ }^{* * * *} \mathrm{P}<0.001\right.$ vs. control) SMA salt, 7-O-succinyl macrolactin A tromethamine salt.
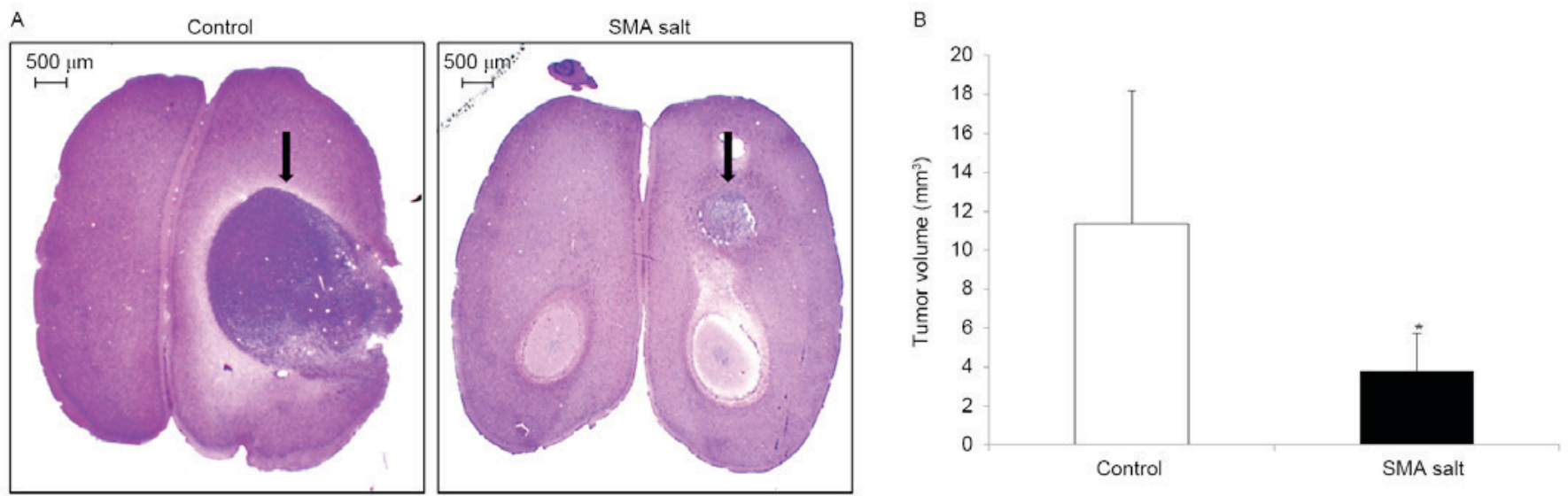

Figure 3. The tumor volume was analyzed 1 month subsequent to tumor cell (U87MG) implantation. The U87MG cell line was cultured in medium and was implanted in the brain of mice. (A) Hematoxylin and eosin stained coronal histological section of mouse brain. Scale bar indicates $500 \mu \mathrm{m}$, the black arrow indicates tumor volume of mice implanted with U87MG cell line. (B) Brain tumor sizes were measured at their largest diameter. All values represent the mean \pm standard deviation of seven independent experiments analyzed by the Student's t-test. ${ }^{*} \mathrm{P}<0.05$. SMA salt, 7-O-succinyl macrolactin A tromethamine salt.

\section{Discussion}

Glioblastoma is the most malignant type of World Health Organization Grade 4 infiltrative gliomas and is associated with a median survival of less than two years $(13,14)$.
Current standard therapies for glioblastoma include maximal safe surgical resection, radiation and temozolomide chemotherapy (2). Temozolomide induces apoptosis by disrupting DNA transcription and inducing DNA damage (15). Despite aggressive treatment, glioblastoma patients commonly exhibit 


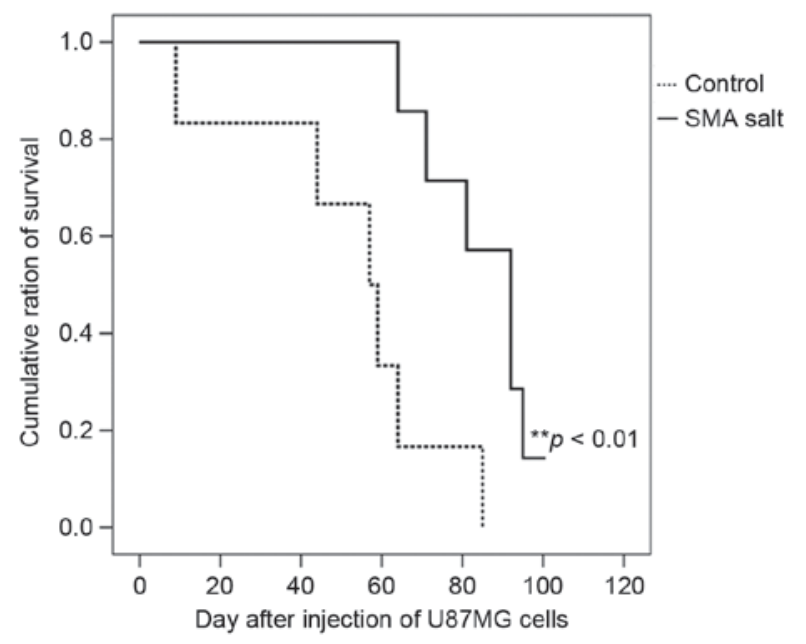

Figure 4. Kaplan-Meier analysis was performed to determine the probability of survival of tumor-bearing mice. The Kaplan-Meier survival analysis reveals significantly prolonged survival in the SMA salt group $(n=7)$ compared with the control group $(n=6)$. ${ }^{* *} \mathrm{P}<0.01$. SMA salt, $7-\mathrm{O}$-succinyl macrolactin A tromethamine salt.

resistance to temozolomide treatment and generally survive no more than two years following diagnosis (3-5,16-18). The migration and invasion of glioblastoma cells is a possible explanation for this resistance. The migration and invasion of glioblastoma cells are the primary reasons for tumor recurrence and poor prognoses (19). The morbidity and high recurrence rate of glioblastoma is largely attributable to the migration and invasion of cells into adjacent brain structures $(20,21)$. Glioblastoma can be accompanied by a high proliferation rate and invasion into surrounding normal brain tissue, which results in tumor recurrence subsequent to the surgical resection of the primary tumor (22). Therefore, innovative therapeutic approaches for targeting these invasive cells are required to enhance clinical outcomes (23).

Studies are now targeted at identifying new therapeutic drugs and discovering novel potential combination therapies to accompany temozolomide or other agents for glioblastoma. In a previous study, we determined that the combination of cilengitide with belotecan, which is a new synthetic analog of camptotein, exhibited a significant antitumor effect on glioblastoma (11). However, although the combination of cilengitide with temozolomide chemoradiotherapy demonstrated potential anticancer activity in phase I and II studies in newly diagnosed glioblastoma $(18,24-27)$, this combination had negative outcomes in phase III trials (28). In addition, combination therapy with bevacizumab and temozolomide chemoradiotherapy in patients with glioblastoma did not improve survival time in phase 3 studies $(29,30)$. Although there have been numerous trials using several antitumor agents, all outcomes have been insufficient or yielded negative results. Thus, novel agents or combination therapies are constantly being investigated and developed for glioblastoma treatment.

SMA is a macrolide compound that is a derivative of MA from Bacillus polyfermenticus KJS-2 (31). SMA has antibacterial and immunosuppressive activities against vancomycin-resistant enterococci and methicillin-resistant Staphylococcus aureus $(6,31)$. SMA also inhibits the proliferation of B16-F10 cells and T-lymphoblast cells against human HIV viral replication (31); additionally, it inhibits the proliferation of neuronal cells against glutamate toxicity (32). SMA is also known to possess effective antibacterial properties (6). SMA also exhibits inhibitive effects on cancer cell invasion and angiogenesis $(8,9)$. In addition, SMA markedly inhibits cell mobility in human fibrosarcoma cells in a concentration-dependent manner (8). Currently, MA and SMA are being assessed in preclinical studies as antitumor and anti-macular degeneration agents at Daewoo Pharmaceutical Ind. Co., Ltd. (Gimhae, Korea) (33). Therefore, the present study investigated the possibility of utilizing SMA as new antitumor agent for glioblastoma.

The present study, determined that SMA salt has cytotoxic effects in glioblastoma cell lines in a dose- and time-dependent manner. It was demonstrated that SMA salt also exhibits an antitumor effect in an in vitro Transwell assay and in a mouse glioma model using U87MG cells. In glioblastoma cell lines, SMA salt clearly reduced cell migration and invasion in a concentration-dependent manner in spite of its own cell mobility character. In particular, at concentrations $>10 \mu \mathrm{M}$, SMA salt exhibited inhibition rates of migration and invasion that were above $50 \%$ in all glioblastoma cell lines. In the in vivo assays, a significant decrease in tumor volume was noted in the group that was treated with SMA salt. Furthermore, this treatment prolonged the survival time of tumor-bearing mice compared with control group. Therefore, the combination therapy of SMA salt and temozolomide can be expected to exhibit cytotoxic effects and may become a successful treatment for patients with glioblastoma in the future.

However, due to the limitations of the U87MG xenograft animal model, the anti-migration and anti-invasion activity of SMA salt was unable to be confirmed in vivo. The human U87MG xenograft model is the standard method for glioblastoma animal models (34-36); however, tumor invasion in this model is not as extensive as spontaneous glioblastomas in humans (37-43). To the best of our knowledge, it is currently unknown how SMA salt is regulated in glioblastoma. Additional studies should be conducted to demonstrate mechanism of the anti-cancer effect of SMA salt and identify the anti-tumor activity of SMA salt in the patient-derived xenograft cancer model. Additional studies are planned to study the effects of SMA salt in more detail to clarify the potential for SMA salt in glioblastoma.

The present study demonstrated the in vitro and in vivo effects of SMA salt in experimental glioblastoma. These effects may be attributed to the inhibition of migration and invasion by SMA salt as well as the cytotoxicity of the drug. Thus, these results suggest that SMA salt has a significant antitumor effect on glioblastoma and may be a promising candidate for additional clinical studies.

\section{Acknowledgements}

The authors would like to thank the Daewoo Pharmaceutical Ind. Co., Ltd. (Busan, Republic of Korea) for donating the SMA salt. The present study was supported by grants from the Seoul National University Bundang Hospital Research Fund (grant nos. 03-2012-007 and 03-2013-007). 


\section{References}

1. Jemal A, Murray T, Ward E, Samuels A, Tiwari RC, Ghafoor A, Feuer EJ and Thun MJ: Cancer statistics, 2005. CA Cancer J Clin 55: 10-30, 2005.

2. Stupp R, Mason WP, van den Bent MJ, Weller M, Fisher B, Taphoorn MJ, Belanger $\mathrm{K}$, Brandes AA, Marosi $\mathrm{C}$, Bogdahn U, et al: Radiotherapy plus concomitant and adjuvant temozolomide for glioblastoma. N Engl J Med 352: 987-996, 2005

3. Tate MC and Aghi MK: Biology of angiogenesis and invasion in glioma. Neurotherapeutics 6: 447-457, 2009.

4. Grauer OM, Wesseling P and Adema GJ: Immunotherapy of diffuse gliomas: Biological background, current status and future developments. Brain Pathol 19: 674-693, 2009.

5. Kim DH, Kim HK, Kim KM, Kim CK, Jeong MH, Ko CY, Moon KH and Kang JS: Antibacterial activities of macrolactin $\mathrm{A}$ and 7-O-succinyl macrolactin A from Bacillus polyfermenticus KJS-2 against vancomycin-resistant enterococciand methicillin-resistant Staphylococcus aureus. Arch Pharm Res 34: 147-152, 2011.

6. Romero-Tabarez M, Jansen R, Sylla M, Lünsdorf H, Häussler S, Santosa DA, Timmis KN and Molinari G: 7-O-Malonyl macrolactin A, a new macrolactin antibiotic form Bacillus subtilis active against methicillin-resistant Staphylococcus aureus, vancomycin-resistant Enterococci, and a small-colony variant of Burkholderia cepacia. Antimicrob Agents Chemother 50: 1701-1709, 2006.

7. Park S, Regmi SC, Park SY, Lee EK, Chang JH, Ku SK, Kim DH and Kim JA: Protective effect of 7-O-succinyl macrolactin A against intestinal inflammation is mediated through PI3-kinase/Akt/mTOR and NF- $\kappa \mathrm{B}$ signaling pathways. Eur J Pharmacol 735: 184-192, 2014.

8. Chung SU, Hwang SW, Ji YH, Kang JS, Kang KR, Kang UR, Kim DH and Kim JA: Anti-angiogenic composition containing macrolactin a and a derivative thereof as active ingredients. Patent WO2012008674 A1. Filed February 23, 2011; issued January 19, 2012.

9. Kang Y, Regmi SC, Kim MY, Banskota S, Gautam J, Kim DH and Kim J: Anti-angiogenic activity of macrolactin A and its succinyl derivative is mediated through inhibition of class I PI3K activity and its signaling. Arch Pharm Res 38: 249-260, 2015.

10. Regmi SC, Park SY, Kim SJ, Banskota S, Shah S, Kim DH and Kim JA: The anti-tumor activity of succinyl macrolactin A is mediated through the $\beta$-catenin destruction complex via the suppression of tankyrase and PI3K/Akt. PLoS One 10: e0141753, 2015.

11. Kim YH, Lee JK, Kim B, DeWitt JP, Lee JE, Han JH, Kim SK, Oh CW and Kim CY: Combination therapy of cilengitide with belotecan against experimental glioblastoma. Int J Cancer 133 749-756, 2013

12. Schmidt KF, Ziu M, Schmidt NO, Vaghasia P, Cargioli TG, Doshi S, Albert MS, Black PM, Carroll RS and Sun Y: Volume reconstruction techniques improve the correlation between histological and in vivo tumor volume measurements in mouse models of human gliomas. J Neurooncol 68: 207-215, 2004.

13. Dirks PB: Brain tumor stem cells: The cancer stem cell hypothesis writ large. Mol Oncol 4: 420-430, 2010.

14. Bar EE, Lin A, Mahairaki V, Matsui W and Eberhart CG: Hypoxia increases the expression of stem-cell markers and promotes clonogenicity in glioblastoma neurospheres. Am J Pathol 177: 1491-1502, 2010.

15. Bei R, Marzocchella L and Turriziani M: The use of temozolomide for the treatment of malignant tumors: Clinical evidence and molecular mechanisms of action. Recent Pat Anticancer Drug Discov 5: 172-187, 2010.

16. Hegi ME, Diserens AC, Gorlia T, Hamou MF, de Tribolet N, Weller M, Kros JM, Hainfellner JA, Mason W, Mariani L, et al: MGMT gene silencing and benefit from temozolomide in glioblastoma. N Engl J Med 352: 997-1003, 2005.

17. Sher DJ, Henson JW, Avutu B, Hochberg FH, Batchelor TT, Martuza RL, Barker FG II, Loeffler JS and Chakravarti A: The added value of concurrently administered tomozolomide versus adjuvant temozolomide alone in newly diagnosed glioblastoma. J Neurooncol 88: 43-50, 2008.

18. Stupp R, Hegi ME, Neyns B, Goldbrunner R, Schlegel U, Clement PM, Grabenbauer GG, Ochsenbein AF, Simon M, Dietrich PY, et al: Phase I/IIa study of cilengitide and temozolomide with concomitant radiotherapy followed by cilengitide and temozolomide maintenance therapy in patients with newly diagnosed giloblastoma. J Clin Oncol 28: 2712-2718, 2010.
19. Chintala SK, Tonn JC and Rao JS: Matrix metalloproteinases and their biological function in human gliomas. Int J Dev Neurosci 17: 495-502, 1999.

20. Cifarelli CP, Titus B and Yeoh HK: Cadherin-dependent adhesion of human U373MG glioblastoma cells promotes neurite outgrowth and increases migratory capacity: Laboratory investigation. J Neurosurg 114: 663-669, 2011.

21. Konakondla S and Steven A. Toms: Cerebral connectivity and high-grade gliomas: Evolving concepts of eloquent brain in surgery for glioma. AIMS Med Sci 4: 52-70, 2017.

22. Gilbert MR, Friedman HS, Kuttesch JF, Prados MD, Olson JJ, Reaman GH and Zaknoen SL: A phase II study of temozolomide in patients with newly diagnosed supratentorail malignant glioma before radiation therapy. Neuro Oncol 4: 261-267, 2002.

23. Davis FG and McCarthy BJ: Current epidemiological trends and surveillance issues in brain tumors. Expert Rev Anticancer Ther 1: 395-401, 2001.

24. Nabors LB, Mikkelsen T, Rosenfeld SS, Hochberg F, Akella NS, Fisher JD, Cloud GA, Zhang Y, Carson K, Wittemer SM, et al: Phase I and correlative biology study of cilengitide in patients with recurrent malignant glioma. J Clin Oncol 25: 1651-1657, 2007.

25. Reardon DA, Fink KL, Mikkelsen T, Cloughesy TF, O'Neill A, Plotkin S, Glantz M, Ravin P, Raizer JJ, Rich KM, et al: Randomized phase II study of cilengitide, an integrin-targeting arginine-glycine-aspartic acid peptide, in recurrent glioblastoma multiforme. J Clin Oncol 26: 5610-5617, 2008.

26. Nabors LB, Mikkelsen T, Hegi ME, Ye X, Batchelor T, Lesser G, Peereboom D, Rosenfeld MR, Olsen J, Brem S, et al: A safety run-in and randomized phase 2 study of cilengitide combined with chemoradiation for newly diagnosed glioblastoma (NABTT 0306). Cancer 118: 5601-5607, 2012.

27. Gilbert MR, Kuhn J, Lamborn KR, Lieberman F, Wen PY, Mehta M, Cloughesy T, Lassman AB, Deangelis LM, Chang S and Prados M: Cilengitide in patients with recurrent glioblastoma: The results of NABTC 03-02, a phase II trial with measures of treatment delivery. J Neurooncol 106: 147-153, 2012.

28. Stupp R, Hegi ME, Gorlia T, Erridge SC, Perry J, Hong YK, Aldape KD, Lhermitte B, Pietsch T, Grujicic D, et al: Cilengitide combined with standard treatment for patients with newly diagnosed glioblastoma with methylated MGMT promoter (CENTRIC EORTC 26071-22072 study): A multicentre, randomised, open-label, phase 3 trial. Lancet Oncol 15: 1100-1108, 2014.

29. Chinot OL, Wick W, Mason W, Henriksson R, Saran F, Nishikawa R, Carpentier AF, Hoang-Xuan K, Kavan P, Cernea $\mathrm{D}$, et al: Bevacizumab plus radiotherapy-temozolomide for newly diagnosed glioblastoma. N Engl J Med 370: 709-722, 2014.

30. Gilbert MR, Dignam JJ, Armstrong TS, Wefel JS, Blumenthal DT, Vogelbaum MA, Colman H, Chakravarti A, Pugh S, Won M, et al: A randomized trial of bevacizumab for newly diagnosed glioblastoma. N Engl J Med 370: 699-708, 2014.

31. Gustafson K, Roman M and Fenical W: The macrolactins, a novel class of antiviral and cytotoxic macrolides from a deep-sea marine bacterium. J Am Chem Soc 111: 7519-7524, 1989.

32. Kim H, Kim W, Ryoo I, Kim C, Suk J, Han K, Hwang S and Yoo I: Neuronal cell protection activity of macrolactin A produced by Actinomadura sp. J Microbiol Biotechnol 7: 429-434, 1997.

33. Bae SH, Kwon MJ, Park JB, Kim D, Kim DH, Kang JS, Kim CG, Oh E and Bae SK: Metabolic Drug-Drug Interaction Potential of Macrolactin A and 7-O-Succinyl Macrolactin A Assessed by Evaluating Cytochrome P450 Inhibition and Induction and UDP-Glucuronosyltransferase inhibition in vitro. Antimicrob Agents Chemother 58: 5036-5046, 2014.

34. Keffer J, Probert L, Cazlaris H, Georgopoulos S, Kaslaris E, Kioussis D and Kollias G: Transgenic mice expressing human tumour necrosis factor: A predictive genetic model of arthritis. EMBO J 10: 4025-4031, 1991.

35. Conrad C, Miller CR, Ji Y, Gomez-Manzano C, Bharara S, McMurray JS, Lang FF, Wong F, Sawaya R, Yung WK and Fueyo J: Delta24-hyCD adenovirus suppresses glioma growth in vivo by combining oncolysis and chemosensitization. Cancer Gene Ther 12: 284-294, 2005.

36. Jiang H, Gomez-Manzano C, Alemany R, Medrano D, Alonso M, Bekele BN, Lin E, Conrad CC, Yung WK and Fueyo J: Comparative effect of oncolytic adenoviruses with E1A-55kDa or E1B-55kDa deletions in malignant gliomas. Neoplasia 7: 48-56, 2005. 
37. Samoto K, Ehtesham M, Perng GC, Hashizume K, Wechsler SL, Nesburn AB, Black KL and Yu JS: A herpes simplex virus type 1 mutant with gamma 34.5 and LAT deletions effectively oncolyses human U87 glioblastomas in nude mice. Neurosurgery 50: 599-606, 2002.

38. Kirsch M, Strasser J, Allende R, Bello L, Zhang J and Black PM: Angiostatin suppresses malignant glioma growth in vivo. Cancer Res 58: 4654-4659, 1998.

39. Lund EL, Bastholm L and Kristjansen PE: Therapeutic synergy of TNP-470 and ionizing radiation: Effects on tumor growth, vessel morphology, and angiogenesis in human glioblastoma multiforme xenografts. Clin Cancer Res 6: 971-978, 2002.

40. Schmidt NO, Ziu M, Carrabba G, Giussani C, Bello L, Sun Y, Schmidt K, Albert M, Black PM and Carroll RS: Antiangiogenic therapy by local intracerebral microinfusion improves treatment efficiency and survival in an orthotopic human glioblastoma model. Clin Cancer Res 10: 1255-1262, 2004.
41. Candolfi M, Curtin JF, Nichols WS, Muhammad AG, King GD Pluhar GE, McNiel EA, Ohlfest JR, Freese AB, Moore PF, et al: Intracranial glioblastoma models in preclinical neuro-oncology: Neuropathological characterization and tumor progression. J Neurooncol 85: 133-148, 2007.

42. Bernstein JJ, Goldberg WJ, Laws ER Jr, Conger D, Morreale V and Wood LR: C6 glioma cell invasion and migration of rat brain after neural homografting: Ultrastructure. Neurosurgery 26: 622-628, 1990.

43. Chicoine MR and Silbergeld DL: Invading C6 glioma cells maintaining tumorigenicity. J Neurosurg 83: 665-671, 1995. 